\title{
Reflections On Resistance, Decolonization, and the Historical Trauma of Libraries and Academia Nicola Andrews
}

In this personal narrative, I will draw on my own lived experiences in order to illustrate how libraries uphold colonialism, and then explore Historical Trauma Theory (HTT) as a framework for healing within library and academic spaces. Within the framework of HTT, the work of indigenous scholars such as Maria Yellow Horse Brave Heart and Linda Tuhiwai Smith has allowed me to begin to understand my struggles and experiences within the context of intergenerational and systemic barriers to academic inclusion. In addition to these indigenous frameworks, considering Sara Ahmed's concept of conditional hospitality within academia has also been useful to me in reflecting on how welcome I feel within academic spaces. The processes of decolonization and reflection are ongoing and uncomfortable, but identifying theories that are grounded in the collective experience of indigenous peoples and feminist activists has renewed my energy for this work, and has provided me with language to describe my experiences in an academic context. In particular, I will reflect on my overlapping identities as a Māori living in Washington State, where I study online at the University of Washington Information School and work towards a Master of Library and Information Science degree. My identity is intersectional, political, and shifting, with aspects of it obscured or exposed depending on my environment and the expectations of my role within it. I am an indigenous, immigrant, queer, woman-ofcolor, and a first-generation high school graduate. As a migrant to this country, I am an outsider; yet as a Māori, I feel an affinity toward other 
indigenous peoples, and the similar struggles of our sovereignties under colonization.

I grew up in Auckland, Aotearoa, raised by my Pākehāe mother, after my Māori father was incarcerated. My parents suffered from alcoholism - my father, a truck driver, died of cirrhosis of the liver two years ago. My mother, a receptionist, still struggles with alcoholism, leading to her own failing health, financial instability, and lack of community.

In this environment, my younger brother and I experienced poverty, exposure to criminal activity, and regular physical and psychological abuse. Addiction is complex, and along with her abusive or erratic behavior, my mother also demonstrated resilience, creativity, and care in seeking out resources and assistance, which included resources made available by public libraries. Under my mother's care, I grew up disconnected from my Māori whānau, ${ }^{2}$ and without learning Te Reo Māori ${ }^{3}$ and Tikanga Māori. ${ }^{4}$ The lack of Māori or Pacific Island teachers or library professionals in my education only reinforced the colonial biases of my classes. Māori library collections were relegated to mythology and folklore, instead of a dynamic and current body of knowledge. Racist attitudes were also widespread in the news; and Mãori and Pacific Islanders were largely absent in the media, unless shown as assisting colonial settlers, leading sports teams to victory, or starring in governmental awareness campaigns - depicted as prime candidates for ill health, drug abuse, teen pregnancy, unemployment, incarceration, lack of education, and lack of financial literacy. Positive role models were in short supply, as were any signs that my Māori heritage was of value to society. ${ }^{5}$

Like many mixed-race or indigenous people who may be ambiguous in appearance and alienated from their traditional values, my sense of identity and belonging was fractured, and I have spent much of my life uncomfortable in identifying either as Mãori or Pākehā. It is only as an adult that I have begun the process of decolonizing myself, building community, and resisting the harmful beliefs and perceived norms I had internalized in my youth.

While I am more than the sum of these identifiers and experiences, they have shaped my ability to move through the world, and how others

\footnotetext{
1 A New Zealander of European descent.

2 Family.

3 The Māori language.

4 Māori protocol.

5 As an adult, I am fortunate to have supportive networks which include my elders, many Māori and Pasifika librarians, and professional organizations such as Te Rōpū Whakahau.
} 
perceive me and my abilities. I offer my testimony ${ }^{6}$ not to solicit pity or admiration but as an act of resistance, to demonstrate that I and others like me are working to indigenize libraries, and make them environments we can actively contribute to, instead of being only tolerated as passive visitors.

In the context of my experiences, my participation in academia is inherently political. I have experienced many tensions in the form of simultaneous privileges and oppressions, and expectations regarding how I perform race and queerness change with my environment and how safe I may feel in it. A full scholarship aimed at Māori and Pasifika students in low-decile areas allowed me to go to university after high school, which would not have been an option otherwise. However, the academic options offered by this small university were very limited, and combined with continued familial stressors, my undergraduate experience was ultimately a poor one, with multiple peers in my scholarship cohort choosing not to continue to struggle towards graduation. I have since had the privilege to emigrate to another country, but have suffered consistent microaggressions, racism, and isolation as a result. With an undergraduate GPA too low to apply to the one institution in Aotearoa that offers a Master of Information Studies degree, I have been fortunate in being accepted to a highly regarded American university ${ }^{8}$ — with a tuition rate five times the amount I would pay back home.

My acceptance within libraries and academia is a form of "conditional hospitality." Sara Ahmed describes the concept of conditional hospitality as the acknowledgement that people are welcomed into cultures or institutions, but are then required to give back in return. More specifically, Ahmed says, "People of color are welcomed on condition they return that hospitality by integrating into a common organizational culture, or by "being" diverse, and allowing institutions to celebrate their diversity." 10 This results in extra emotional labor for minoritized people in academia. My education is dependent on integration with the norms of colonial pedagogy, which at best ignores indigenous knowledge, and at worst, is detrimental to it. Despite their progress toward becoming safe and inclusive spaces, libraries

6 Linda Tuhiwai Smith, Decolonizing Methodologies: Research and Indigenous Peoples (London: Zed Books, 1999), 144.

7 Every five years, the Ministry of Education calculates the decile ranking of schools in Aotearoa, which measures the socio-economic position of a school's community relative to other schools in the nation; this is used to indicate the school's need for funding. The decile scale places the most in-need schools at a rank of "1," and those with little to no need at a rank of "10." The high school I attended has a current decile rank of "3."

8 The UW iSchool Admissions Committee considers applicants on a case-by-case basis, with a holistic application process which includes a personal statement and supplemental questions.

9 Sara Ahmed, On Being Included: Racism and Diversity in Institutional Life (Durham, NC: Duke University Press, 2012), 42.

10 Ahmed, 43. 
and universities operate as sites that have contributed to the colonization and trauma of indigenous communities, and have long served to assist indigenous assimilation into majority culture. Ways that spaces of learning accept and reinforce oppression and white supremacy can include continued occupation of stolen indigenous land (with or without acknowledgement); or the naming of mascots, buildings, or monuments for colonizers, Confederate soldiers and sympathizers, or those complicit in slavery or racism. Minoritized students and employees are to assume that they are truly welcomed, even if celebration of their differences is never explicitly stated, and if oppressive normativity continues to be insidiously embedded into the culture of the institution. ${ }^{11}$ Furthermore, these traumas are revisited every time an institution fails to condemn racial violence, whether in the form of a discriminatory governmental order, growth of intimidating graffiti in library spaces and materials, or white supremacists speaking at or marching on university campuses. While these instances are awful and have increased since the 2016 United States presidential election, each one is an opportunity for libraries and universities to offer unwavering support and affirmation of our core values to our communities, and when only silence results, it is as alienating as it is deafening. ${ }^{12}$

The risk that I assume to fulfill a future livelihood as a librarian is not one that is equally assumed by the academy. Tuition rates demand that I must already have significant means, that my financial and immigration status are such that I am able to secure a federal loan, or that I am successful in securing scholarships, graduate assistantships, or some other employment. Failure to do so risks perpetuating the poverty and trauma experienced within my family. In relation to the investment of tuition and time necessary to enter the profession, librarianship is a relatively low-paying field. Those who seek to become a subject specialist are often required to possess a second graduate degree in another discipline, increasing the risk of falling into debt. Additionally, it is expected that new graduates - particularly those seeking employment within academic libraries - be willing to relocate to accept employment. In many cases, new, migrant, or indigenous librarians must assume additional financial

11 April Hathcock, "Whiteness and 'Oppressive Normativity,"' At the Intersection (blog), April 21, 2016, https://aprilhathcock.wordpress.com/2016/04/21/whiteness-and-oppressive-normativity/.

12 The Association of Research Libraries is an example of an institution which has demonstrated bold leadership in consistently releasing public statements unequivocally denouncing racism and affirming social justice and equity. See, for example, Chris Bourg, "Research Libraries and Archives Stand Committed to Diversity, Inclusion, Equity, Social Justice," ARL News, November 16, 2016, http://www. arl.org/news/arl-news/4154-research-libraries-and-archives-stand-committed-to-diversity-inclusionequity-social-justice\#.WhNDtVWnFhE. 
risks, sever the only support systems and community they have, and accept work in an environment where they may feel compelled to downplay aspects of their identity to fit in. There is also the risk of early burnout, given that minoritized librarians are often called upon to undertake diversity and outreach work in their institution, in addition to their hired duties.

Like many others before me, I have had to improvise to make the most of my learning opportunities. Incorporating indigenous knowledge into my degree required me to be proactive in finding practical ways to supplement the online curriculum that was available to me. For example, to further learn about Mātauranga Māori, ${ }^{13}$ I took a day trip to the University of British Columbia to attend a public lecture by visiting Māori LIS scholar, Dr. Spencer Lilley. I embarked upon a three-week study abroad exploration seminar, to learn about Chamorro knowledge from the people of Guåhan. This trip was crucial to my understanding how colonialism has led to the occupation of Guåhan by the United States military, and how the economic and patriotic incentivization of Chamorro towards military service is at odds with the lack of voting rights or veteran support extended to those on the island. In my final year, I undertook an unpaid internship with the Burke Museum of Natural History and Culture, in addition to completing a quarter-long class project working with the Burke's collection of Māori taonga. ${ }^{14}$ During this time, I researched metadata terms in Te Reo Māori, and made suggestions on how Māori taonga might be displayed after completion of the new Burke Museum in 2019. My aim was to encourage more strongly identifying the Rangatira ${ }^{15}$ associated with these taonga within the context of their land and ancestors - reframing Māori taonga within a Māori worldview, and promoting engagement with whanau around the globe. These experiences have been vastly beneficial and have grown my community of support, validated my interest in researching indigenous knowledge within LIS, and have provided opportunities to consider traditional storytelling, art, service, and wayfinding in ways that are not consistently reflected in my MLIS program. My colleague Jessica Humphries and I-the only indigenous students in our online cohort of 76 students - have both taken on many extra-curricular activities to interact with the communities we most wish to uphold through library work. In purposefully seeking out indigenous knowledge, we could converse with several communities through experiential learning and conference presentations; and critically engage with impacts of colonialism, including university admissions standards, voting

13 Traditional Māori knowledge.

14 Treasure; precious items ranging from language to physical artifacts.

15 High-ranking person. 
rights, what is privileged as valid knowledge, and cultural appropriation and repatriation.

While I am proud of the work I have done, at times it also proved overwhelming, and I regret that my university was not able to provide me with direct support or more opportunities to use indigenous knowledge. This lack of support meant that there were also relevant research projects that I was not able to fully pursue during my degree. Supplementing my curriculum required me to take unpaid leave from my minimum-wage, non-benefit jobs; and juggling scholarship conditions and conference preparations meant that at times my schoolwork needed to be completed to a higher standard, yet in less time than that of my peers. Conditional hospitality dictates that it is the oppressed who must risk their position in advocating for change, and that the burden of extra work falls to those whose professional identities do not conform to the majority. However, as my studies have concluded, my university has changed, including a curriculum audit and the recent appointment of two Assistant Professors of Native North American Indigenous Knowledge. I am hopeful that those who begin the MLIS program after me will be able to choose to fully engage with indigenous knowledge as a research interest.

I am grateful to have been awarded grants, scholarships, and fellowships, but it must be noted that these too are offered with conditional hospitality - with obligations including writing thank you letters or reports, specific academic load and grade requirements, networking, and availability to travel and attend events, on top of work, school, and other commitments. These academic and professional development opportunities have enhanced my sense of community, ${ }^{16}$ ability, and financial security, but the institutions offering them have also benefitted from my participation in outreach efforts and committees, inclusion in marketing collateral, and a general example of the presence and success of diversity initiatives. While I do not consider this "performing whiteness," vancement within academia requires prioritizing individual achievement over the collective well-being, and proficiency in colonized systems of knowledge, in opposition to indigenous values.

As I have begun to reflect on how colonialism manifests within the education system, it has not been difficult to come up with examples that illustrate colonialism in practice. Throughout my graduate education, I

\footnotetext{
16 Deep gratitude to my mentors, Robin Chin Roemer, Amanda Hornby, Sandy Littletree, and Helene Williams.

17 April Hathcock, "White Librarianship in Blackface: Diversity Initiatives in LIS," In the Library with the Lead Pipe, October 7, 2015, http://www.inthelibrarywiththeleadpipe.org/2015/lis-diversity/.
} 
have become increasingly concerned with who we as future information professionals are being prepared to serve, whose values are being reinforced, and whose needs are privileged. For example, current admissions standards do not allow all students the luxury of choosing an institution that may best suit their learning goals and needs. ${ }^{18}$ As a profession, how does this support our nebulous goals around diversity recruitment? Additionally, within librarianship, talk of mentorship and support remains largely focused on undergraduates, but those who carry trauma or who come from backgrounds not typically reflected within academia and librarianship require support at all points of our careers, not simply at a high school or undergraduate level. Throughout my degree, students are urged to overcome impostor syndrome, and yet are continually "othered" when their perspectives are not reflected within the academy. In my experience, this could look like the same group of three or four cohort members pushing to talk about social justice or critical librarianship in multiple class settings, with no facilitation offered by professors to reduce microaggressions or increase understanding, or online students being excluded from invitations to faculty candidate presentations which are routinely attended by residential students. Lastly, while I do not expect classes at American universities to address Māoritanga, what about the indigenous students upon whose traditional lands campuses have been built? If libraries continue to operate as sites of colonization in themselves, why would we choose to be their patrons and employees?

\section{Library Spaces and Historical Trauma Theory}

With no shortage of critiques towards academia and librarianship, a profession I have chosen and am passionate about, it is comforting to be able to seek solutions that are both grounded in indigenous knowledge and operate within academia. Through the scholarship of Maria Yellow Horse Brave Heart, ${ }^{19}$ I have been able to consider Historical Trauma Theory (HTT) in thinking about how potential library users and library professionals encounter barriers to participation within libraries. HTT is a framework that has been used to understand the intergenerational impacts on large groups of people who have suffered multiple and collective traumas.

\footnotetext{
18 Of the 59 institutions in North America that offer an ALA-accredited MLIS qualification, only 23 will consider applicants with a GPA of under 3.0, only ten of which offer an online mode of delivery. Nicola Andrews, Jessica Humphries, "Negotiating Indigeneity: Fostering Indigenous Knowledge within LIS Curricula," (presentation, IFLA WLIC, Columbus, OH, August 17, 2016). Despite being one of these, statistics for the UW MLIS program note that in recent years, enrollment by all ethnic groups other than Caucasian have declined. Kari Brothers, e-mail message to author, November 14, 2016.

19 Maria Yellow Horse Brave Heart et al., "Historical Trauma among Indigenous Peoples of the Americas: Concepts, Research, and Clinical Considerations," Journal of Psychoactive Drugs 43 (2011): 288.
} 
Originally focusing on trauma carried by survivors of the Holocaust, Yellow Horse Brave Heart has also applied this theory to indigenous survivors of colonization and their descendants. In this regard, "Historical trauma theory frames lifespan trauma in the collective, historical context, which empowers Indigenous survivors of both communal and individual trauma by reducing the sense of stigma and isolation." ${ }^{20}$ Closely linked to this is Unresolved Grief Intervention, ${ }^{21}$ a radical approach also by Yellow Horse Brave Heart, which aims to allow expression and resolution of intergenerational grief which has previously been repressed or invalidated.

HTT can help explain how the devaluing of indigenous languages, cultures, and protocols has resulted in trauma within indigenous families, which continues to manifest itself in subsequent generations. Indigenous peoples have suffered adverse impacts of colonization which include loss of sacred lands, religion, and language, and forced participation in native schools. These histories can deeply impact indigenous identity and selfworth, as well as student engagement and perceived ability within education; I have seen this in practice in multiple generations of my family. For modern day curricula and institutions to treat indigenous people and their values as an afterthought is a subtle, yet clear continuation of these colonial power dynamics. This can then be applied to both libraries and LIS-granting institutions within the academy. Brave Heart asserts that conditions for healing require reconciliation of the values that have been lost — such as the thoughtful weaving of indigeneity within curriculum, pedagogy, and faculty. ${ }^{22}$ If we want to permanently increase diversity within the profession, then institutions must make the profession an environment that unconditionally welcomes and values different perspectives and backgrounds.

\section{Approaches Toward Healing}

Although challenging, there are ways that indigenous values and perspectives can be centered within LIS. After examining publiclyavailable syllabi for 60 institutions throughout North America and Aotearoa that offer LIS credentials, it appears that indigenous knowledge

\footnotetext{
20 Maria Yellow Horse Brave Heart et al., "Historical Trauma Among Indigenous Peoples of the Americas," 283.

21 Maria Yellow Horse Brave Heart et al., "Historical Trauma Among Indigenous Peoples of North America," 285.

22 Maria Yellow Horse Brave Heart, "The Return to the Sacred Path: Healing the Historical Trauma and Historical Unresolved Grief Response Among the Lakota Through a Psychoeducational Group Intervention," Smith College Studies in Social Work 68, no. 3 (1998), 302.
} 
systems and communities are seldom part of the LIS curriculum. However, some institutions do offer classes as electives, such as "Maori Information Sources" at Victoria University of Wellington, ${ }^{23}$ or "Indigenous Systems of Knowledge" at The University of Washington, ${ }^{24}$ albeit not regularly. ${ }^{25}$ What is more effective in cultivating a deeper understanding of indigenous viewpoints and issues is to intentionally ground an entire degree within an indigenous framework. Some examples I have found include the University of British Columbia's First Nations Curriculum Concentration within the Master of Library and Information Studies degree, ${ }^{26}$ or the Master of Social Work, Indigenous Trauma, and Resiliency offered by the University of Toronto. ${ }^{27}$

In addition to introducing concepts around indigenous knowledge within tertiary education, it is vital that these concepts be applied in practice, and routinely measured or reflected upon. Among the requirements for Professional Registration of credentialed library professionals in Aotearoa is the completion of a portfolio demonstrating eleven "Bodies of Knowledge," with the eleventh body focusing on Māori research methodologies, Mātauranga Māori, and actively implementing Tikanga Māori where appropriate. ${ }^{28}$ Simple yet meaningful ways for libraries and academic institutions to make themselves more welcoming to indigenous people can include using indigenous languages for signage and names of spaces and services, in consultation with local tribal nations. ${ }^{29}$

Historical Trauma Theory and Unresolved Grief Intervention promotes healing through evaluating and reporting intergenerational traumatic experiences, which has led to increased self-worth, value of indigenous identity, increased productivity, and improved personal relationships in participants. Libraries can also demonstrate respect of indigenous knowledge by ensuring collections reflect contemporary stories and research by indigenous authors, not simply outdated or exoticizing texts in

23 “INFO 530," Victoria University of Wellington, accessed January 30, 2017, http://www.victoria.ac.nz/ courses/info/530/2015/offering?crn=10566.

24 "MLIS Projected Course Schedule," University of Washington Information School, last modified July 26, 2017, https://ischool.uw.edu/current/mlis/course-schedules/mlis-projected

25 According to course catalogs, "Maori Information Sources" is offered biannually and taught online; "Indigenous Systems of Knowledge" alternates between being offered online and on campus.

26 "First Nations Curriculum Concentration," The University of British Columbia, accessed January 30, 2017, http://slais.ubc.ca/programs/degree-specializations/first-nations-curriculum-concentration/.

27 "MSW Indigenous Trauma and Resiliency," Factor-Inwentash Faculty of Social Work University of Toronto, accessed January 30, 2017, http://socialwork.utoronto.ca/admissions/msw-itr/.

28 “Bok 11," LIANZA, accessed January 30, 2017, http://www.lianza.org.nz/bok-11.

29 Admittedly, this is more easily achieved in Aotearoa, where Te Reo Māori is an official language and there are fewer sovereign nations to compete for government resources. 
ethnography or folklore. In thinking beyond collections and towards creating an environment that actively considers the needs of indigenous staff and patrons, I was encouraged to see that the Edmonton Public Library has launched an Elder in Residence program. ${ }^{30}$ Elder Wilson Bearhead will offer programming to both the community and the library staff, in response to the need for increased understanding around indigenous perspectives and the Truth and Reconciliation Commission of Canada's Calls to Action. ${ }^{31}$ Additionally, the Edmonton Public Library website features the option to browse content by an "Indigenous" filter, which leads to events, staff picked materials, and resources that directly address themes including trauma, reconciliation, and oral tradition through hip-hop, as well as language resources in Cree, Chipewyan, and Inuktitut. It can be difficult to have an honest and ongoing dialogue about the injustices of colonialism in a public space, but I am confident that the community that may result from the initial discomfort of healing will be vastly more rewarding than the occasional book display or cultural food event.

Linda Tuhiwai Smith emphasizes the importance of acknowledging that every indigenous person has value, and knowledge - and then sharing that knowledge for the collective good. ${ }^{32}$ While it may seem obvious that every person has knowledge, this may not be instinctual for those whose families have had to choose between being punished for using their knowledge, such as Te Reo Māori, or keeping it from other generations to ensure their safety and social mobility. However, healing is possible. Our profession and the institutions we support can meaningfully acknowledge our history, and work to alleviate colonization. Many of my colleagues are the first in their families for whom interest and opportunity have aligned to result in higher education. It has taken a lot of resilience for me to navigate the culture, challenges, and opportunities of graduate school, and yet I speak from a place of relative privilege and success. In speaking about my experiences, I have had other students respond by also resolving to push themselves beyond discomfort to ensure their own prosperity. However, bootstrap mentality is something we should work to eradicate-simply

\footnotetext{
30 “Elder in Residence Program,” Edmonton Public Library, accessed January 30, 2017, https://www.epl.ca/elder-in-residence/.

31 "Elder in Residence Program." The Truth and Reconciliation Act aims to inform all Canadians about the history of Indian Residential Schools (IRS), in order to facilitate reconciliation and respect between Aboriginals and other Canadians.

32 Linda Tuhiwai Smith, "Decolonizing Knowledge: Toward a Critical Indigenous Research Justice Praxis," in Research Justice: Methodologies for Social Change, ed. Andrew J. Jolivétte (Bristol: Policy Press, 2015), 208.
} 
surviving in academia and accepting it is a stressful environment is too low a bar to set. Those who have experienced oppression are not fatalistic victims, but nor should they solely bear the burden of creating space for themselves within the dominant culture. If institutions and those on their fringes cannot work together to make academia more dynamic and inclusive, then the tensions I have described will always be present. However, when the full and painful truths of our histories are acknowledged by majority cultures and governing institutions, it becomes easier for all of us to move past them, and start building a future together. 


\section{Bibliography}

Ahmed, Sara. On Being Included: Racism and Diversity in Institutional Life. Durham, NC: Duke University Press, 2012.

Andrews, Nicola, and Jessica Humphries. "Negotiating Indigeneity: Fostering Indigenous Knowledge within LIS Curricula.” Presentation at IFLA WLIC, Columbus, OH, August 17, 2016.

Brave Heart, Maria Yellow Horse. "The Return to the Sacred Path: Healing the Historical Trauma and Historical Unresolved Grief Response among the Lakota through a Psychoeducational Group Intervention." Smith College Studies in Social Work 68, no. 3 (1998): 287-305. doi:10.1080/00377319809517532.

- —_ "The Historical Trauma Response among Natives and its Relationship with Substance Abuse: A Lakota Illustration." Journal of Psychoactive Drugs 35, no. 1 (2003): 7-13. doi:10.1080/0279107 2.2003.10399988.

Brave Heart, Maria Yellow Horse, Josephine Chase, Jennifer Elkins, and Deborah B. Altschul.

"Historical Trauma among Indigenous Peoples of the Americas: Concepts, Research, and Clinical Considerations." Journal of Psychoactive Drugs 43, no. 4 (2011): 282-90. doi:10.1080/02791 072.2011.628913.

Brave Heart, Maria Yellow Horse, and Lemyra M. DeBruyn. "The American Indian Holocaust: Healing Historical Unresolved Grief." American Indian and Alaska Native Mental Health Research 8, no. 2 (1998): 60-82.

Cavino, Hayley. "Intergenerational Sexual Violence and Whanau in Aotearoa/New Zealand - Pedagogies of Contextualisation and Transformation." Sexual Abuse in Australia and New Zealand 7, no. 1 (2016): 4-17.

Hathcock, April. "White Librarianship in Blackface: Diversity Initiatives in LIS.” In the Library with the Lead Pipe, October 7, 2015. http://www.inthelibrarywiththeleadpipe.org/2015/lis-diversity/.

Pihama, Leonie, Cherryl Smith, Paul Reynolds, Linda Tuhiwai Smith, John Reid, and Rihi Te Nana. "Positioning Historical Trauma Theory Within Aotearoa New Zealand." AlterNative 10, no. 3 (2014): 248-62. http://www.content.alternative.ac.nz/index.php/alternative/article/view/259/307.

Smith, Linda Tuhiwai. "Decolonizing Knowledge: Toward a Critical Indigenous Research Justice Praxis." In Research Justice: Methodologies for Social Change, edited by Andrew J. Jolivétte, 205-11. Bristol: Policy Press, 2015.

___ Decolonizing Methodologies: Research and Indigenous Peoples. London: Zed Books, 1999. . "Imagining Our Own Approaches." Cataloging \& Classification Quarterly 53, nos. 5-6 (2015): 473-74. https://doi.org/10.1080/01639374.2015.1027982.

Wirihana, Rebecca, and Cherryl Smith. "Historical Trauma, Healing, and Well-Being in Māori Communities.” Mai Journal3, no. 3 (2014): 198-210. http://www.journal.mai.ac.nz/sites/default/ files/MAI_Jrnl_3\%283\%29_Wirihana02.pdf. 